\title{
ACORDOS PRA A UNIFICACIÓN LINGÜÍSTICA DAS COLABORACIÓS DA HISTORIA DE GALIZA, DIRIXIDA POR D. RAMÓN OTERO PEDRAYO
}

DOI: 10.17057/fmfhv.2021.015

Tomados por consenso entre os participantes, en reunión celebrada en Ourense o 22 de maio de 1956. Consérvase a copia manuscrita de Aquilino Iglesia Alvariño, encargado de tomar nota dos acordos e de sistematizalos nunha proposta que sería ratificada; esta copia, con emendas manuais, figura no Fondo Fernández del Riego [ES.GA.36057.AFFR_017424] e foi tida en conta polos editores para a fixación do texto.

Esta edición baséase na copia mecanoscrita, que pon en limpo e fixa o texto da anterior, pois esa foi a que circulou entre os autores. Consérvase no Fondo Otero Pedrayo da Fundación Penzol [ES.GA.36057.AFP 2.1.2.10.2.3.5.2 CA-0702/005/001]. 

1. Os escritores galegos firmantes, chamados pra redactar un directorio que dera certa unidade ós traballos de colaboración desta magna obra que vai ser editada en Bos Aires, no que se refire á aqueles aspectos da lengua que andan en libre xogo, na xunta celebrada na ciudade de Ourense o dia 22 de maio de 1956, estiveron conformes por maioría nos puntos que siguen.

2. Non cabe impór unha ortografía de pretensiós centíficas, ríxida e universal, visto que os escritores non son lingüistas sempre, e teñen un sentimento da súa lengua tan propio que chega a variar en cada ún e en cada obra.

3. O criterio adoptado non é ${ }^{1}$ filolóxico-histórico, senón práctico. Tense en conta que hai en uso criterios diversos, todos eles coas súas razós a favor. Non cabe discutilos, xa que nin siquera están na misma liña de discusión. Sólo diante do feito dunha obra en colaboración, nacida en unidade de espíritu e de amor, faise obrigado achegar eses criterios o máis que se poida, sacrificando cada un algo do seu, á espera de que se vaia impoñendo o dos grandes escritores.

\section{CULTISMOS}

4. Revisóuse en primeiro lugar o problema da trascripción dos cultismos, sabendo que teñen que ser moitol-os empregados nesta obra e tendo en conta o valor desta especie de moeda internacional da cultura. Aceptóuse o principio establecido nas normas do Seminario de Estudos galegos en 1933: «Nas verbas cultas mantéñense os grupos primitivos: obviar, apto» ${ }^{2}$. Este principio enténdese así:

\footnotetext{
1 Na copia manuscrita, da man de Aquilino Iglesia Alvariño, «no é», consonte o precepto (42) a recomendación feita na aliña (41) do resumo; produciuse a mesma modificación en «no é doado» (7) e «no é raro» (20), o segundo con $-n$ cancelado expresamente [Nota dos editores].

2 Estaba prevista unha nota a rodapé, probablemente coa referencia bibliográfica, que non se chegou a redactar [Nota dos editores].
} 
5. Cando se faga uso dunha palabra que non figure na historia do galego nin teña, polo tanto, forma vulgar ou semiculta na lengua viva, non debe o escritor evolucionala pola súa conta, limitándose, a suprimil-o que repune a fonética galega, asegún o que logo se di.

\section{PREFIXOS CULTOS}

6. $A B$ - trascribirase $a b$ en absurdo, abnegado, cultismos, mentras que se escribirá asolto e ausolver, por seren formas semicultas en uso. Da misma maneira, $A D-$ conservarase en adversario, adverso, etc., frente á aveso e os semicultismos popularizados, ademitir, adevertir, adeministración.

Os prefixos que máis se tiveron en conta foron:

- PRAE-, que non se debe trascribir por per como se ten feito en palabras como percepto, perciso, percavido, $\mathrm{e}$

- PRO-, que tampouco cabe trascribir en metátesis, por-. Porveito, porcurar ou porferir serían vulgarismos sin xustificación na obra de que se trata.

- Os prefixos DIS-, IN-, INTER-, SUB-, SUPER- deben trascribirse na forma orixinal cando se trate de verdadeiros cultismos: disiuntivo, inquisitivo, intersticio, subversión, supernal.

7. O prefixo $E X$-, seguido de consonante acordouse trascribilo por ex-, visto que non é doado confundir nesta posición o seu son co do $-x$ - galego. Seguido de vocal pode confundirse, pero sendo tan característico este cultismo e tan doado de conocer, acordouse tamén deixalo na forma orixinaria. Escribirase, pois, excoriación, extranxeiro, exacción, exacto.

8. TRANS- acordouse trascribilo por tras-, debido a ser este prefixo vivo na fala de cada día. Así, trasporte, trasmisión.

\section{SUFIXOS E TERMINACIÓS CULTAS}

9. Pensouse sobre todo nos sufixos que deron formas históricas vulgares, moi características en galego, pero que non cabe levar hoxe sobre os mismos sufixos orixinarios, visto que se perdéu a concencia lingüística da sua identidade. Estes sufixos orixinarios son, entre outros da misma serie: 
- -ATICU: en vulgar, -ádigo e -ado; en culto -ático (extático).

- -ANTIA: en vulg. -anza; en culto -ancia (costancia).

- -ENTIA: en vulg. -enza; en culto -encia (evidencia).

- -ATIONE: en vulg. -azón; en culto -ación (prelación).

- -ITIA: en vulg. -iza; en culto -icia (ictericia).

- -ITIONE: en vulg. -izón; en culto -ición (prescripción).

- -ACEU: en vulg. -azo; en culto -áceo (herbáceo).

- -ARIU: en vulg. -eiro; en culto -ario (herbolario).

- -ORIU: en vulg. -ouro; en culto -orio (purgatorio).

- -ANEU: en vulg. -año; en culto -aneo (contemporáneo)

- -INO: en vulg. -iño; en culto -ino (leporino)

Tratánse o mismo os que, sin vir citados, pertenezan á serie -io, -ione, -ia.

10. Introdúcese algunha variante de trato nos sufixos ou terminacios que siguen:

- Os en -MINE, trascribiranse por -me (réxime)

- Os en -BILE, [trascribiranse] por -bele (amábele)

- Os en -CE, [trascribiranse] por $-z$ (capaz)

11. Os en -TATE, -TUTE trascribiranse normalmente por -tade, -tude (libertade, xuventude), debendo saberse que a forma xeneralizada en -tá, -tú provén da lengua oficial.

12. A pesar do dito, acórdase que o nome de Galiza quede fora da lei xeneral

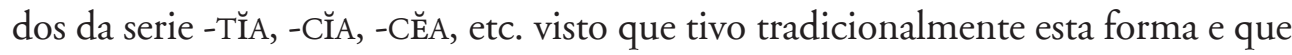
os grandes escritores a mantiveron frente á restitución que operóu a lengua oficial.

13. Tendo en conta tamén que os semicultismos estudo [e] estudante están moi extendidos e deu nome o primeiro a unha ilustre institución de Galiza, ademítense como sustantivos, pero non como formas verbales.

\section{SUFIXOS VULGARES DOBLES}

14. Non se recomenda uniformal-as terminaciós alternantes -ao, -au, -an, nin certas palabras como bo e bon, có, coio e cón, podendo escribirse de tódal-as maneiras. Con todo a forma más, fem. de mau, en plural, analóxica do fem. en -á, como chás de chá, irmás de irmá, considérase local (Ferrol) e non se ademite na obra que se trata de editar. 


\section{O PLURAL}

15. Non se consideran máis que os casos dudosos. Fora deles o galego sigue as normas da lengua oficial.

16. Os acabados en vocal acentuada faráno sempre en -s, sin excepción.

17. Os acabados nos diptongos -au (maus), -eu (bucaréus), -ou (bous) fano en -s. Os acabados en -ai (pais), -oi (bois) fano tamén en -s, pero non así os monosílabos en -ei (reises, leises) que teñen un vulgar en -ses e outro normal (reis, leis) que é o que usaremos.

18. Os acabados en $-l$, sobre todo os cultos, fan o plural en -es: papeles, nabales, xinoles. Pero debe saberse que hai formas consagradas en -ás, que deben manterse, como reás, animás, currás, etc. Hai outras en -ais (curráis), que se estiman localismos (Valdeorras) e que deben evitarse nesta obra, o mismo que os literarios en -ls (nabals).

19. Os acabados en - $n$ farán o plural en -ns nos escritores que usen o sufixo -an derivado de -ANU. Se de irmán se fai irmans, farase de un, uns, de función, funcions e de parabén, parabens. Pero se se fai uso do sufixo -ao,-au, derivado de -ANU, toda a serie fará o plural en $-s$, con perda do -n. Se de irmao se fai irmaos, de un, us; de función, funciós; de folgazán, folgazás; de parabén, parabés. Tamén neste caso se dan como localismos os plurales en -ais, -eis, -ois dos acabados en - $n$.

\section{FORMACIÓN DO FEMENINO}

20. O galego non se aparta neste punto da lengua oficial, a non ser nos derivados do sufixo -ANU e nos acabados en - $n$, en xeneral. Cando -ANU fai - $a o$, - $a u$, como irmáu, chao, o femenino parece ser en -a: irmá, cha. Se fai -án, non varían no femenino: miña irmán, pedra chan.

Os derivados do sufixo -ANEM, de tipo despectivo, fano en -a: de folgazán, folgazana, según o que se puido observar.

Os feitos, así e todo, aparecen confusos, e non é raro atopare femeninos de -ao, -au, en -ana: de mourao, mourana, de ribeirao, ribeirana.

As cousas así, acordouse que

a) Os acabados en -au, -ao, fagan sempre o femenino en -á: ribeirao - ribeirá, irmau - irmá. 
b) Os acabados en -on, en -oa: bon - boa, ladrón - ladroa, lambón - lamboa.

c) Os acabados en -án, alternados con -ao, -au, que non varían: meu irmán miña irmán; trovador cortesán - lírica cortesán; home cristián e muller cristián.

Non se pensa que deban ser tratados do mismo xeito

d) Os femeninos de nomes en -án derivados de -ANEM, polo que de folgazán se dirá folgazana.

e) Especial atención merecen os xentilicios de -an e -ANU orixinarios. Aparte os en -án (catalán, alemán) os derivados de -ANU son todos cultismos, debendo escribirse, polo tanto, americano, mexicano, etc. Non caben, según deixamos dito, as formas vulgares en -ao, -au. E, sendo así, o femenino ten que sere en -a: americana, mexicana. E por non complical-os feitos, debe facerse en - $a$ tamén o femenino dos en -an: catalana, alemana. De Castela, o xentilicio histórico é castelao, polo que o femenino será castelá. Ningunha destas formas é hoxe vixente, pero deben preferirse nunha obra histórica.

\section{FENÓMENOS FONÉTICOS}

21. Reconócese a existencia de vocales abertos e zarrados $(e, o)$, pero acórdase non marcalos por esta sola razón.

22. Reconócese tamén que hai un $i$ vocal (vivo) e outro consonante (maio, $i$-anga). Pero acordouse por maioría non distinguilos na escritura.

23. bis Entre o artículo $a$ i a $a$-tónica inicial e, nas formas verbales, entre $a$ tónica final e o pronome átono $o, a, o s$, as, desenrólase un $i$ consonántico que se debe manter, separado por guión, no primeiro caso (a i-alma, a i-auga), e, xunto, no segundo (faraio, diraio).

24. bis Por razós distintas, tamén se desenrola un - $n$ - entre o $i$ e o $u$ desinencial do perfecto da primeira conxugación e os pronomes xa ditos (ameino, amouno). Tampouco se debe separar.

25. bis $\mathrm{O}$ son do $c h$ latino ou do $\chi$ grego, en palabras cultas, represéntase por $c$ diante $a, o, u$, ou consonante (calcídica, crisólogo) e por qu-diante $e$, i (quelidro, quelonio). Exceptúanse os semicultismos en uso: ciruxía, celidonia. 
26. bis Os cultismos gregos en -is (neurosis, crisis, etc.) están tomados do nominativo e no hai por qué non mantelos.

23. Non se recomenda nada sobor do - e paragóxico, tratándose dunha obra como a que temos en conta; nin acerca do infinitivo desinencial (facermos, facerdes, faceren). Pero reconócese que a fonética e a sintaxis galega padecen de non marcarmos estes fenómenos.

24. Ademítense as variantes locales de algús verbos, como ser, estar, facer, traer, etc., con tal que señan formas vivas e realmente locales (seña, seia, sea; estiven, estuven; andiven, anduven; ficen, fixen; trouxen, truxen). Pero non a de si e se, conxunción, adoptándose se.

25. O $H$ ten valor fonético peculiar en unha, ningunha, etc. Marca a articulación velar do - $n$ - intervocálico. Fora deste caso é un sino etimolóxico que non se corresponde en moitos casos co da lengua oficial.

26. Ó $X$ reconocéronselle dous valores: o vulgar de $c h$ francesa e o culto de $c s$ ou gs, pero non o de -is- ou -ns- dos semicultismos vulgares eisame ou ensame.

27. Tamén se lle reconocen dous valores a $C$ e $Z$, un normal e outro de $s$, extendido pola Galiza atlántica. Por esta razón de ter doble valor $C$ e $Z$ aconséllase non facer uso de $s$ en voces como luz, cruz, ainda que se pronuncien lus e crus, nin tampouco noutras, como zoco, zugar, que teñen orixe etimoloxico en palabras que comenzan por s-, visto que o s- inicial tivo moi distintas evoluciós i, entre elas, a de $z$ (zarrar, zanfona, zucio).

\section{GRUPOS CONSONÁNTICOS CULTOS}

28. Sostense o criterio seguido cos prefixos e sufixos: esto é, mantelos. Exemplos: BS: absolver; $\mathrm{BD}$ : subdirector; $\mathrm{BM}$ : submarino; $\mathrm{BR}$ : subraiar; $\mathrm{BS}$ : subsistir, $\mathrm{BV}$ : subvertir. СТ: acto, efecto. GN: maligno, pugna; MN: amnistia; NM: inmaculada; $\mathrm{NN}$ : innoble; PC: erupción; PS: eclipse; PT: aptitude; TL: atlas; TM: ritmo; TN: etnógrafo; BST: abstención; BSTR: obstrucción.

29. Os grupos $B L, C L, F L$ e $G L$ tenden a trocarse en $b r, c r$, fr e $g r$. Pero non é preceptivo, xa que non é lei xeneral en toda a historia do galego, facer este cambio en voces cultas.

30. Nos grupos NST, NSP, NSC, o $n$ non ten valor fonético en galego, polo que se pensóu en suprimilo i escribir costante, trasporte, trascendente. 
31. Reconócese que moitos destes grupos teñen tratamento especial na fala de cada día, oíndose ás veces formas como oustáculo, suvención, autividá, amídala, autitú, oución, Mansimino, etc. Non se pode dar norma fixa neste punto. Se a palabra é de uso común, como ausilio, másimo, amidala, suvención, ousequio, e non se desvía moito na forma e no son, pode aceptarse como un semicultismo. En caso contrario, hai que reducila sempre ó tipo orixinario, sobre todo se forma parte do fondo común da cultura como tal cultismo. Según esto, non se deberá escribir mánsimo, visto que as grandes lenguas da cultura a trascriben na forma etimolóxica, anque sí másimo, seguindo a norma que se tivo en conta para os grupos -NST-, -NSP-, que sigue tamén o italiano, de non trascribil-o son que se elimina na articulación normal.

32. Certos semicultismos popularizados deben manterse, distinguindo ben as formas populares dos vulgarismos. Puxéronse como exemplos: ademiración, adeministración, doutor, iñorar e iñorante, referidas ós grupos -DM-, -CT- e -GN-.

\section{CONTRACCIÓS E ASIMILACIÓS}

33. A preposición a e o artículo determinado $o$, $a$, os, as, contránse en $o ́$, á, ós, ás, que se escribirán con acento agudo.

34. A misma preposición e o artículo indeterminado, un, unha e tamén os pronominales outro, outra, contráense en ón, ónha, autro, autra. Pero estas contracciós considéranse localismos e non deben facerse.

35. A preposición de contraise con artículos, pronominales e algús adverbios. Deben manterse estas contracciós na forma que indicamos: do, da, dos, das, dun, dunha, deste, dese, daquel, dalgún, dalguén, doutro, doutrora, daqui, dalí, dalá.

36. As contracciós de con son éstas: co, coa, cun, cunha, coeste, coese, coaquél, coalguén.

37. As de en son doutro tipo, pero faranse do mismo xeito: no, nun, neste, nese, naquel, nalgún, nantontre, noutro e nestoutro.

38. As contracciós destas preposiciós con sustantivos, adxetivos e verbos non deben facerse: está en Ourense, con ollos doces.

39. Toda voz acabada en $-s$ ou $-r$ asimilóu este son co $l$ antigo do artículo determinado e do pronome de terceira persona. Ó simplificárense os dous éles 
resultantes, o que restóu apónse na concencia dos nosos escritores á voz que precede, en contra da lei do reparto silábico, pra enchel-o oco que deixa o $s$ ou $r$ asimilado.

As normas que se dan redúcense a tres:

a) Se a asimilación cai diante o pronome, faráse sempre, pero non se marcará: Diolo bendiga, méntrala amaño, canto máila mira, maila quere.

b) Se cai diante o artículo, separaráse éste, na súa forma moderna $(o, a, o s, a s)$ do $l$ primitivo por un guión: Son bol-os toxos; ten clárol-os ollos; comémol-os figos.

c) Se a palabra que sofre asimilación é unha partícula proclítica, xuntarase tamén co artículo: Polo río, tralos valados, o can e mailo gato.

40. Hai contracción entre os pronomes me, che, lle, nos, vos, lles e os átonos $o$, $a$, os, as e dela resultan as formas mo, ma, etc. cho, llo, nolo... volo..., llelo, que se escribirán sempre nesta forma.

41. É semellante a que se dá entre certas desinencias do verbo e os pronomes átonos $o, a$, os, as: (ámalo, amámolo, amádelo, amáchelo, amástelo). Trátase da segunda persona do singular e da primeira e segunda do plural. Escríbense como aquí se fixo.

42. $\mathrm{O}$ - $n$ final de non, ben, quen, ninguén, alguén, desaparece unhas veces e outras forma sílaba coa palabra que sigue. Desaparece diante vocal, $m$ ou $n$. Forma sílaba coa palabra que sigue cando ésta comenza por vocal.

Se predomina a tonicidade da palabra que sigue ou ésta comenza por $m$ - ou n-, pérdese o -n final de non e nin: Que no haxa novedade, no é bo, no me fales, xa no me acordo. A trascripción farase sin ningún sino.

Se predomina a tonicidade de non e nin, por énfasis na articulación, ou se se trata de quen, ben, alguén, etc. o - $n$ final forma sílaba coa vocal da palabra que sigue: nono quero = non o quero; beno vin = ben o vin; quéno dixo = quén o dixo; nino vin, nino quero ver $=$ nin o vin, nin o quero ver. $\mathrm{O}$ exemplo primeiro $\mathrm{e}$ derradeiro, sin énfasis en non e nin, serán: No o quero; ni o vin ni quero ver.

Neste punto acordouse sacrifical-a independencia léxica á realidade fonética, determinando:

a) Que non se marque a perda do -n: no haxa novedade; ni o vin ni o quero vere; no o quero. 
b) Que se xunte nunha sola palabra non, ben, quen, etc., cando o $-n$ forme sílaba con formas pronominales átonas $o$, a, os, as: quéno dixo, beno sei.

c) Expresiós como non os viron e non nos viron, que puideran parecer anfibolóxicas trascritas asegún se indica, nono son. No primeiro caso, se se escribe con énfasis en non, dará ¿¿Nónos viron!? e, sin el no os viron. No segundo, non nos viron con énfasis en non, non pode variar e seguirá escribíndose non nos viron. Sin énfasis será no nos viron, como deixamos dito, [vid.] a). Non cabe confusión.

\section{LETRAS E SIGNOS DE PUNTUACIÓN}

43. Non se fará uso na escritura de $j, y, \epsilon, n h$ e $l h$, como se ten feito nalgús casos. 44. Mantense a ortografía acentual da lengua oficial polo que se refire a voces oxítonas, paroxítonas e proparoxítonas: Finóu, mármore.

45. Mantense tamén no que se refira a $i, u$ tónicas, seguidas de forte: María, túa, súa, lúa.

46. Non se mantén na función diacrítica, fora dos pronomes demostrativos: éste, ése, aquél, dos posesivos: méu, téu, séu, nóso e vóso, e dos interrogativos.

47. Levarán acento agudo as formas contractas ó, á, ós, ás, do no 33: vai á feira, anda ós pertegos.

48. Levarán tamén acento outros contractos como pór (de poñer), sô (de solo), mór de maior, pero nada máis que cando poidan confundirse con outras voces homófonas.

49. Levarán acento nós e vós cando señan tónicos.

50. Non se fará uso do apóstrofo. En caso de sinalefa que non se teña mencionado, escribirase a vocal que corresponda: de hoxe en diante, non d'hoxe en diante.

51. Usarase o guión en dous casos: entre $i$ eufónico de $a$ i-alma, i entre o $l$ de asimilación -s, -r cando sigue artículo determinado: veu vel-o fillo. Hai que segal-a herba. Pois segala. 


\section{RESUME}

1. Os cultismos, sin historia no galego, non poden presentar na súa estructura forma histórica de evolución popular ou vulgar (5)

2. Os sufixos AB, AD, PRAE, PRO, DIS, IN, INTER, SUB, SUPER non deberán ser modificados, en voces cultas: absurdo, adversario, precepto, proveito, disiuntivo, inquisitivo, intersticio, subversión, supernal. Poden ademitirse certos semicultismos de uso común, como ausolver, ademitir, adevertir, adeministración. (6)

3. O prefixo EX- mantense co seu valor culto: excoriación, exánime. (7)

4. TRANS redúcese a tras: trasporte, trasmisión. (8)

5. Os sufixos que deron formas históricas vulgares, non poden reducirse a estas formas en palabras cultas: deste xeito, con -ATICUM faremos estático; con -ANTIA, costancia; con -ENTIA, evidencia; con -ATIONE, prelación; con -ITIA, puericia; con -ITIONE, prescripción; con -ACEUM, herbáceo; con -ARIUM, herbolario; con -ORIUM, purgatorio; con -ANEU, contemporáneo; e con -INO, leporino. (9)

6. O sufixo -INE fará $-e$, ainda que seña en voces cultas: de ORIGINE, orixe; de REGIMINE, rexime. O en -CE, -z: de CAPACE, capaz. (10)

7. Os en -TATE, -TUTE, darán -tade, -tude: libertade, virtude. (11)

8. Escribirase Galiza. (12)

9. Tamén se escribirá estudo e estudante, tratándose de sustantivos. Se é verbo, estudio. (13)

10. Pode escribirse mao, mau ou man. Pero o uso dos singulares exixe que os plurales se acomoden a cada un: mao, maos; mau, maus; e man, mans. (14)

11. As normas do plural son comús case sempre ó galego e ó castelán. (15)

12. En galego, os acabados en vocal tónico fano sempre en -s. (16)

13. Os acabados en aolau, eoleu, ou, ai, oi, fano tamen en -s: maus, bucareus, bous, mais, bois; pero os en -ei teñen un vulgar en -ses, que non debe usarse: reises, leises, ademáis de leis, reis. (17)

14. Os acabados en $l$ teñen plurales tradicionales que deben conservarse: reás, animás, currás, etc. Os de nomes cultos e moitos vulgares son en -es: papeles, nabales, xinoles. Os plurales en -ais, ois, -eis, dos nomes en - $l$ (Valdeorras) non deben usarse, nin tampouco os rosalianos en -als. (18)

15. Os acabados en $-n$, perden o $n$ e apoñen $-s$ nos escritos que usen - $a o$, - $a u$ por -an. Se usan as formas Mao, irmao, o plural de can será cas e o de pan, pas. 
Se usan as formas man, irmán, o plural de todol-os en -n será en -ns: mans, cans, pans, xardins. (19)

16. Os en -ao, -au fan o femenino en -á: irmao - irmá; os en -án alternante con aolau, non varían: meu irmán - miña irmán; os en -an común, en -ana: folgazán - folgazana; os en -on, en -oa: bon - boa. De americano - americana; de catalán - catalana; pero de castelao (arcaico) - castelá. (20)

17. $\mathrm{O} i$ de vivo non ten o mismo son que o de maio, pero deben escribirse o mismo (22).

18. O $i$ eufónico de a i-alma, a i-auga sepárase por guión; o das formas verbales faraio, amaraios, non. (23 bis)

19. O - $n$ - de asimilación de ameino, amouno non se separa do verbo nin do pronome. (24 bis)

20. O son de $c h$ latino pasa ós cultismos por $c$ (diante $a, o, u$ ou consonante) (calcídica, crisólogo) e por qu- (diante e, i): quelonio. Exceptúanse os semicultismos: ciruxía, celidonia e outros que puidera haber. (25 bis)

21. Os cultismos gregos, tomados dos nominativos en -is, manténense así: neurosis. (26 bis)

22. O - e paragóxico e os infinitivos desinenciales sería ben empregalos. (23)

23. Respétense as variantes verbales faguer e facer, seña e seia, andiven e anduven, con tal que señan formas vivas; pero redúzase sempre a se a conxunción si. (24)

24. Escríbase $h$ en $u n h a$, e nos seus derivados e compostos e naquelas voces que a tiveren en latín: Hispano, herdeiro, pero non noutras que a teñen na lengua oficial por outras razós, como oso, ovo, etc. (25)

25. Escríbanse con $x$ as voces cultas que o teñan no seu orixe: axioloxía, hexámetro. (26)

26. Ainda que se reconoce como lexítimo o seséo, escríbanse $c$ e $z$ cando haxa este son no interior de Galiza: zoco, zugar, luz. (27)

27. Os grupos orixinarios de consonantes deben manterse nas voces cultas. (28)

28. Os grupos - bl-, -cl-, - fl- e -gl- poden manterse tamén. No é fenómeno típico galego trocalos en $-b r$, $-c r-$, etc. (29)

29. Os grupos NST, NSP, NSC, poden perdel-o $n$, visto que non sona en galego: costante, trasporte, trascendente. 
30. Os grupos que aparezan tratados polo uso de distinto xeito, en palabras contadas, poden aceptarse como veñan, con tal que a palabra non seña un cultismo universal nin o tratamento seña un puro incultismo. Semicultismos como sumarino, surraiar, másimo poden ademitirse, pero non outros como mánsimo. (31)

31. Deben ademitirse os cultismos popularizados, como ademiración, adeministración, doutor, iñorar e iñorante. (32)

32. Non se escribirá ao, áa, aos, áas e sí ó, á, ós, ás. (33)

33. Escribiráse a un a unha, a outro, a outra e non ón, onha, autro, autra. (34)

34. Manteránse sin apóstrofo as contracciós do, da, dos, dun, dunha, deste, dese, daquel, dalgún, dalguén, doutro, doutrora, daquí, dalí, dalá. (35)

35. Do mismo xeito co, coa, cun, cunha, coeste (coiste), coaquel, coalgún. (36)

36. E tamén no, nun, neste, naquel, nalgún, nantronte. (37)

37. Non se contraerá a preposición con sustantivos, adxetivos ou verbos nin se marcará a sinalefa. (38)

38. $-S$ ou $-r$ finales asimilados en $l$, atrán o pronome átono e o artículo determinado. Este último separaráse cun guión, se o atrai unha palabra tónica: Diolo bendiga; polo río; tralos valados; pero ten clarol-os ollos; comemol-os figos. (39)

39. Non se separen as formas contractas mo, ma..., cho, cha..., llo, lla..., nolo..., volo..., llelo. (40)

40. Dise o mismo das contracciós de desinencia verbal e pronome átono: ámalo..., amámolo..., amádelo..., amáchelo..., amáchedelo ou amástelo. (41)

41. Non, fora de posición enfática, diante vocal, $m$ - ou $n$ - perde o $-n$ final: $N o$ haxa novedade, no me fales, no namora a ninguén.

Recoméndase marcar este fenómeno fonético-sintáctico como se indica. (42)

42. Non, en posición enfática, quen, ben e alguén, xúntan-o -n final coas formas $o$, $a$, os, as do pronome de terceira persona: nono quero, beno vin, queno dixo, algueno dixo.

As expresiós: Non os viron e non nos viron escribiranse así, e poden servir de paradigma:

¿Non os viron? = ¿Nónos viron?

Non os viron $=$ No os viron .

¿Non nos viron? = ¿Non nos viron?

Non nos viron $=$ No nos viron . (42) 
43. Non se fará uso de $j, y, c,-n h$ - ou -lh-. (43)

44. A acentuación, como na lengua oficial. (44)

45. i, u, tónicas, seguidas de forte, acentúanse: María, túa, súa, lúa. (45)

46. O acento diacrítico da lengua oficial non se mantén máis que nos pronomes demostrativos, posesivos e interrogativos, non nos personales: $t u$ ou ti, el ou $i l$, non levan acento. (46)

47. Levan acento as formas contractas ó de $a o, a ́ d$ de $a a$, ós, ás. (47)

48. Levan acento outros contractos como pór (de poñer, só de solo, môr (de maior) cando poidan confundirse con homófonos seus. (48)

49. Acentúanse nós e vós, tónicos. (49)

50. Prescíndese do apóstrofo. (50)

51. Do guión faráse uso en dous casos: a i-alma, a i-auga ( $i$ eufónico) e veu vel-o fillo (artículo con $l$ asimilado). (51)

Escribiu estes acordos

Aquilino Iglesia Alvariño 